\title{
Preload assisted laser thermoforming at low-temperature
}

\author{
Yankuo Guo, Yongjun Shi ${ }^{1 *}$, Xiaogang Wang and Xiaoyu Zhao \\ College of Mechanical \& Electronic Engineering, China University of Petroleum, Qingdao, Shandong 266580, China
}

\begin{abstract}
Laser thermoforming is widely used to produce rapid prototyping parts of sheet metal. Laser multiple scanning or single high-temperature scanning is often used to obtain a large bending angle. This method produces high heating temperature, which destroys the material characteristics and reduces the material use value. A method of forming at low heating temperature is proposed to overcome the aforementioned problems, and the mechanism of thermo-mechanical action is studied. Results show the positive application of preload in the low-temperature forming method can increase the bending angle by up to 39.00 times. The low-temperature forming method is important for reducing energy consumption, protecting workpiece material properties, and applying laser in practical production.
\end{abstract}

\section{Introduction}

Laser heat forming of sheet metal is a flexible process, in which a laser beam is used to induce thermal stresses for generating controlled distortion. In contrast to other forming techniques, this method requires without stamping dies and hard tooling. thus, it is suitable for low-volume production and forming of hard and brittle materials [1-3].

Chan et al. [4] analyzed the microstructure change of a $\mathrm{Ti}_{3} \mathrm{Al}$-based intermetallic alloy in the laser forming, and the results showed that the hardness varies significantly across the sheet thickness. Merklein et al. [5] studied the microstructural development of aluminum and aluminum alloys after laser heating. The different inhomogeneous particles and dislocation structures in addition to the laser parameters influence the strength of the entire composite. Cheng et al. [6] conducted a microstructure analysis of AISI 1010 steel sheet and found a clear boundary with the non-homogenous microstructure around the laser heat-affected zone. The fracture toughness near the center of the heated zone is the highest, whereas that near the boundary of the heated zone is the lowest. Fan and Cheng et al. [7] developed a thermal microstructural mechanical model of AISI 1010 steel in consideration of the effect of phase transformations on the flow stress. The effects of cooling ways on microstructure and mechanical properties were studied using the model. The results showed that the microstructure near the top surface with forced cooling has a more refined bainite phase than that with nature cooling. Furthermore, the hardness increases compared with the raw material because of strain hardening and grain refinement.

\section{Numerical simulation parameters}

The low-temperature forming method is shown with a Cartesian coordinate system in Fig. 1. This process of the method shows as follows.

(1) A sheet metal to be bent is clamped on one side while the three other sides are free.

(2) The uniform line load $q_{F}$ is applied on the free edge parallel to the clamping end. The sheet metal produces the elastic bending deformation, wherein the plastic deformation is non-existent.

(3) A laser beam scan on top surface scans along the heating line parallel to the clamping end with the constant laser parameters. Reasonable processing parameters are used to ensure that the laser scanning peak temperature is at low heating temperature for guaranteeing material property protection.

(4) The heated sheet metal is cooled by natural air. The line load is removed when the sheet metal is sufficient to cool down.

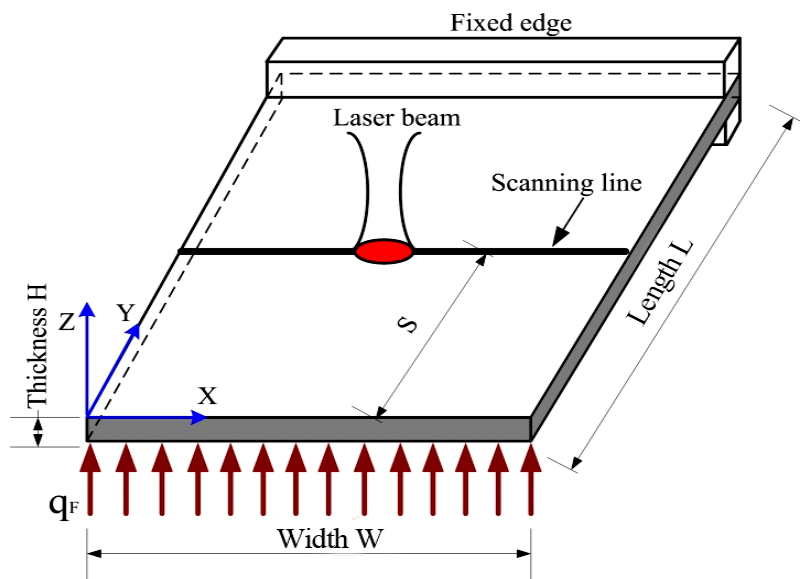

Fig. 1. Forming schematic of a sheet metal at low temperature 
Numerical simulations are performed using the finite element code ANSYS to analyze the deformation behavior of the sheet metal in the laser forming. In this behavior, the temperature and applying preload interact with each other to form a complex thermo-mechanical coupling problem. A three-dimensional thermodynamic coupling model is established. The size of the sheet metal is $40^{*} 40^{*} 2 \mathrm{~mm}$. as shown in Table 1 . The preload applied at the free end of the plate is a uniform wiring load $\mathrm{q}_{\mathrm{F}}$.

Table 1 Simulation parameters

\begin{tabular}{|c|c|c|c|}
\hline Case & $\begin{array}{c}\text { Temperature } \\
\text { value } \\
\mathrm{T}\left({ }^{\circ} \mathrm{C}\right)\end{array}$ & $\begin{array}{c}\text { Temperature } \\
\text { type }\end{array}$ & $\begin{array}{c}\text { Laser } \\
\text { parameters } \\
\mathrm{P}, \mathrm{v}, \mathrm{d} \\
(\mathrm{W}, \mathrm{mm} / \mathrm{s}, \mathrm{mm})\end{array}$ \\
\hline 1 & $\approx 300^{\circ} \mathrm{C}$ & Low & $220,5,6$ \\
\hline 2 & $\approx 400^{\circ} \mathrm{C}$ & Low & $300,5,6$ \\
\hline 3 & $\approx 900^{\circ} \mathrm{C}$ & High & $670,5,6$ \\
\hline
\end{tabular}

\section{Results and discussion}

\subsection{Positive preload}

Fig. 2a shows the z-direction displacement in various process parameters, and Fig. $2 \mathrm{~b}$ presents the corresponding bend angle. Fig. $2 \mathrm{c}$ displays the method of selecting measuring points. This method takes the measuring points from the center of the scan line to the clamping end along the y-direction, with two grid elements apart from each measurement point. The measuring points are numbered 1,2,3, and 4 in turn, and the peak stress at the measuring points during the entire heating time is recorded. The positive applied prestress and thermal stress are both negative. For the sake of simplicity and convenience of comparison, both prestress and thermal stress are taken positive. Comparing without preload bending angles of measuring points 1,2 , and 3 in Fig. $2 b$ indicates that the bending deformation angle increases with temperature increases. Therefore, bending angle $\theta$ is mainly determined by thermal stress. Case 1 (peak temperature of $295{ }^{\circ} \mathrm{C}$ ) and case 2 (peak temperature of $404{ }^{\circ} \mathrm{C}$ ) are low temperature. Thus, the low temperature will form not only a small thermal stress but also a high yield strength value, and these will result in smaller bending angles in the heating zone. In particular, case $1\left(295{ }^{\circ} \mathrm{C}\right)$ forms a bending angle of $0.01^{\circ}$ and thus this angle losts its application value. Case 3 uses a higher temperature value (peak temperature of $913{ }^{\circ} \mathrm{C}$ ) and can form large thermal stress and low yield strength in the heating zone. Thus, this case realizes a large bending angle $\left(0.63^{\circ}\right)$. However the case 3 (peak temperature of $913{ }^{\circ} \mathrm{C}$ ) requires the use of laser processing parameters that produce high temperatures. As a result, the high temperatures will be not economical for saving energy and protection for material performance.
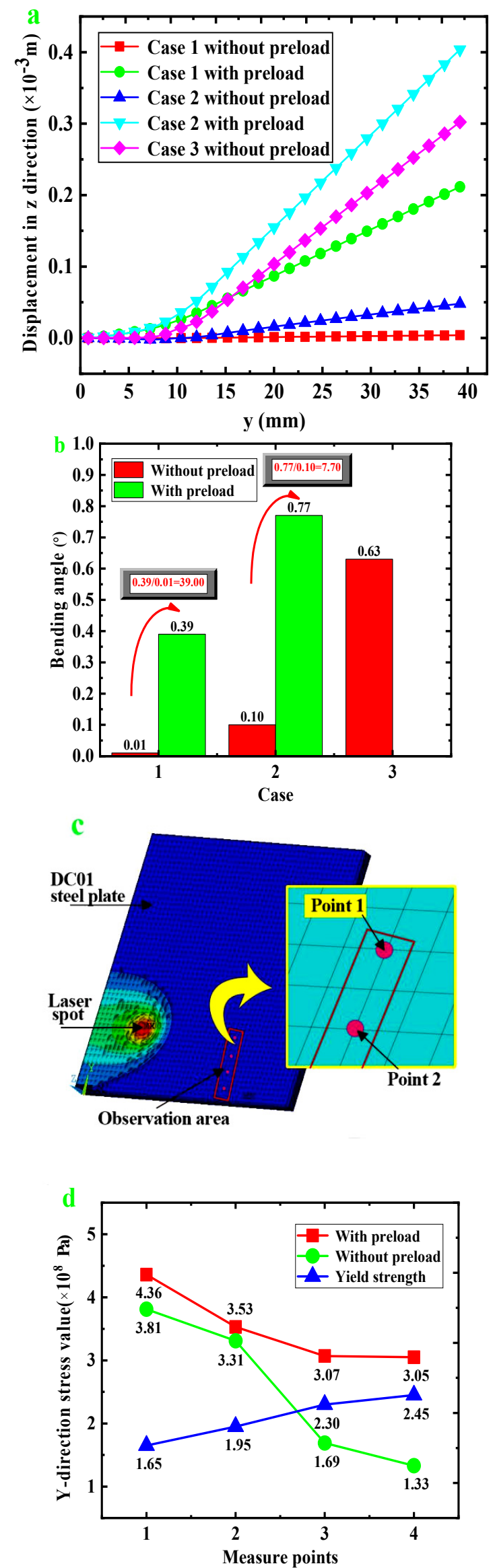

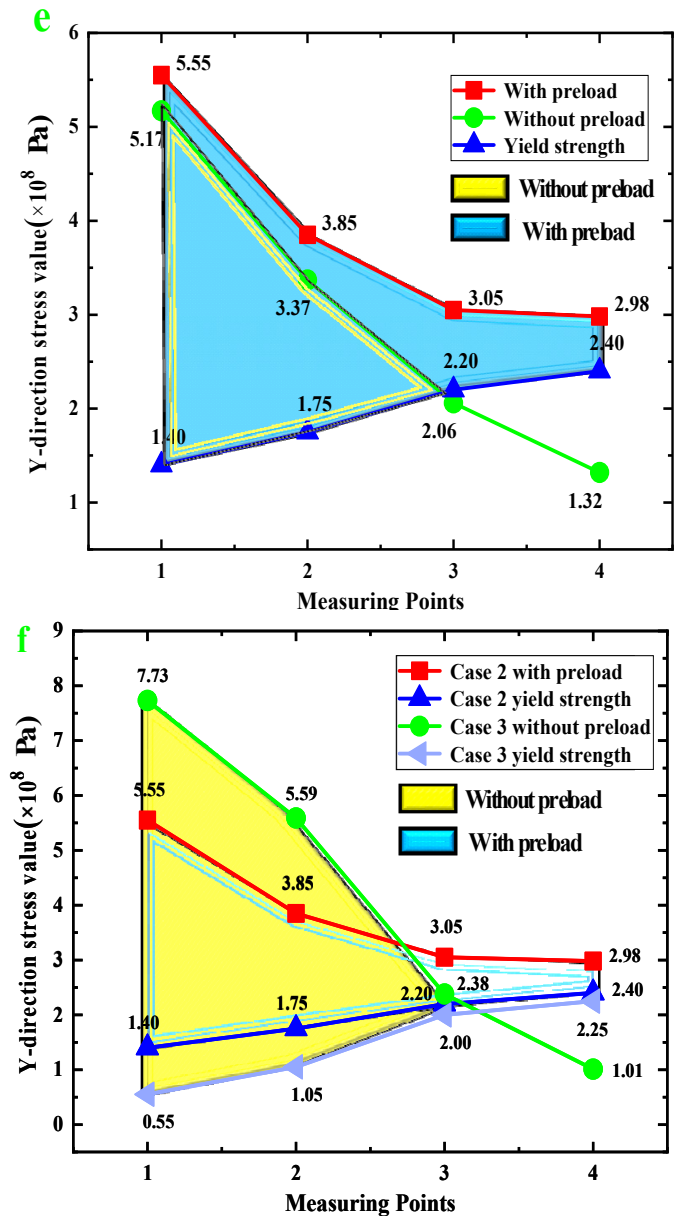

Fig. 2. Comparison of positive preload and without preload a $z$-direction displacement, $\mathbf{b}$ bending angle $\mathbf{c}$ measurement point diagram, $\mathbf{d}$ case 1 with preload and without preload comparison, e case 2 with preload and without preload comparison, and $\mathbf{f}$ case 2 and case 3 comparison

Fig. 2b shows a comparison of the bending angles of cases 1 and 2 without and with preload. From the Fig. 2b, it can be seen that the preload application can greatly increase the bending angle (39.00 and 7.70 times) at the case of low temperature. Figs. $2 d$ and $2 \mathrm{e}$ are comparisons of stress values at cases 1 and 2, respectively, with and without preload at measuring points $1,2,3$, and 4 . By comparing the stress values of the preload and without preload, it can be found that stress values of the preload at the same measuring point are greater than stress values without load. Because of the coupling of prestress and thermal stress, the stress value is greatly increased. Especially at measuring points 3 and 4, the stress value decreases below the yield strength at this temperature without preload, and without plastic bending deformation occurs in the heating zone. The stress value with preload is still larger than the yield strength value at this temperature due to the coupling value of preload. The application of preload extends the area of plastic deformation. Therefore, the addition of preload not only increases the stress value at each plastic deformation point but also extends the length of the deformation area. The reason is that a large plastic deformation angle can be formed in the aforementioned condition[8-9]. Case 2 is used to draw Fig. 2e for intuitively observing the size of the bending angle in preload and without preload. In Fig. 2e, the plastic deformation zone is the shaded area surrounded by the stress value and the yield strength.

As shown in Fig. $2 b$, the bending angle of case 2 $\left(0.77^{\circ}\right)$ with preload at low temperature is $0.14^{\circ}$ larger than that of case $3\left(0.63^{\circ}\right)$ without preload at high temperature. The bending angle of case 2 is 1.22 times higher than that of case 3. Due to the application of preload, a larger bending angle can be achieved in the heating zone with preload at low temperature than in the case without preload at high temperature[10-11]. Fig. $2 \mathrm{f}$ shows a stress values comparison of cases 2 and 3 at different measuring points. By comparing the stress values of Fig. $2 \mathrm{f}$, it can be seen that the coupled stress value (5.55 and $3.85 \mathrm{MPa}$ ) at measuring points 1 and 2 at low temperature is less than that at high temperature (7.73 and 5.59 MPa). However, the thermal stress decreases greatly with the increase in the distance from the scanning center at high temperature without preload. At measuring points 3 and 4, the thermal stress value of case $3(2.38$ and $1.01 \mathrm{MPa})$ at high temperature without preload decreases close to the yield strength $(2.00 \mathrm{MPa})$ and below the yield strength $(2.25 \mathrm{MPa})$. For case 2 of low temperature, the coupling stress value (3.05 and 2.98 $\mathrm{MPa}$ ) is not only higher than the yield strength (2.20 and $2.40 \mathrm{MPa}$ ) but also higher than the thermal stress value of case 3 (2.38 and $1.01 \mathrm{MPa})$. The case 2 of low temperature can still produce plastic deformation at positions 3 and 4 and can greatly improve the bending angle. Therefore, the bending angle of the preload formed at low temperature $\left(300{ }^{\circ} \mathrm{C}-400{ }^{\circ} \mathrm{C}\right)$ requires case at which the traditional laser processing temperature should be higher than $900{ }^{\circ} \mathrm{C}$. In addition, low-temperature preload can effectively avoid the damage of high-temperature to the structure and properties of materials. The low-temperature forming method can not only achieve high bending angle but also protect material properties, and these advantages have great great practical significance.

\subsection{Negative preload}

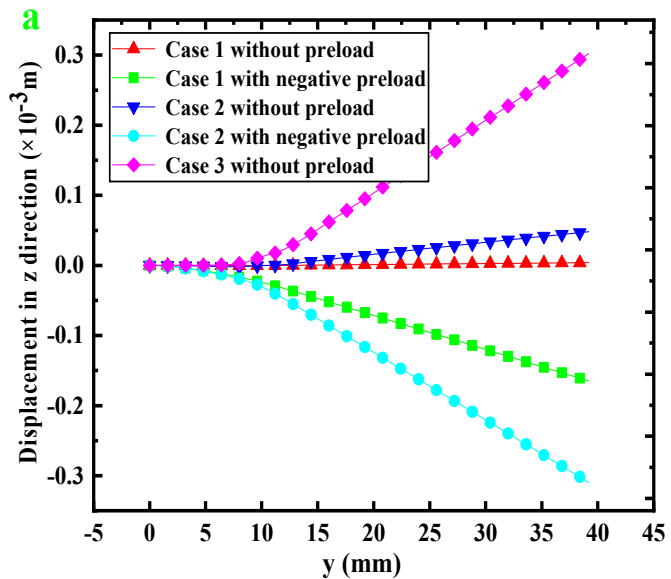




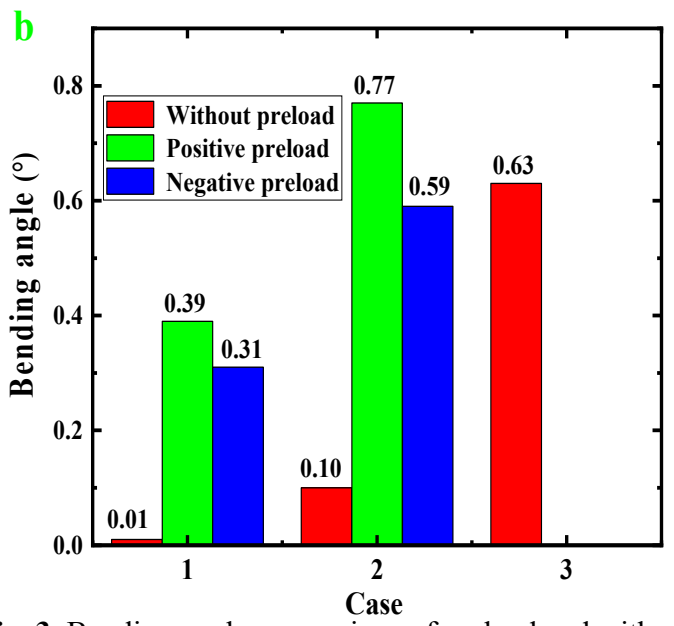

Fig. 3. Bending angle comparison of preload and without preload

a $\mathrm{z}$-direction displacement, and $\mathrm{b}$ bending angle

Fig. 3a shows the displacement in $\mathrm{z}$-direction when the direction of preload is negative $\left(q_{F}=-5000 \mathrm{~N} / \mathrm{m}\right)$. Fig. $13 \mathrm{~b}$ shows the bending angles in the direction of positive, negative, and without preload. The comparison of Fig. 3b shows that the bending angles $\left(0.31^{\circ}\right.$ and $\left.0.59^{\circ}\right)$ applied negatively in cases 1 and 2 are larger than those in cases without preload $\left(0.01^{\circ}\right.$ and $\left.0.10^{\circ}\right)$. Furthermore, the bending angles can be increased ( 31 and 5.9 times) and have a negative direction. Therefore, negative preload can be applied to achieve a large bending angle and negative bending direction simultaneously in the case of low-temperature.
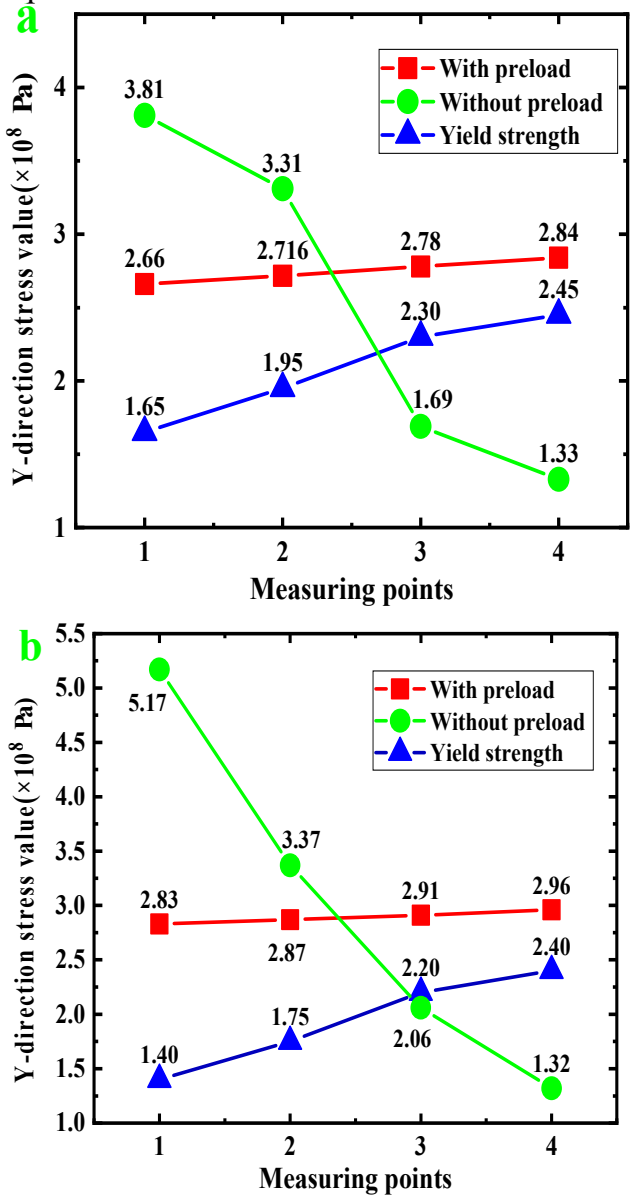

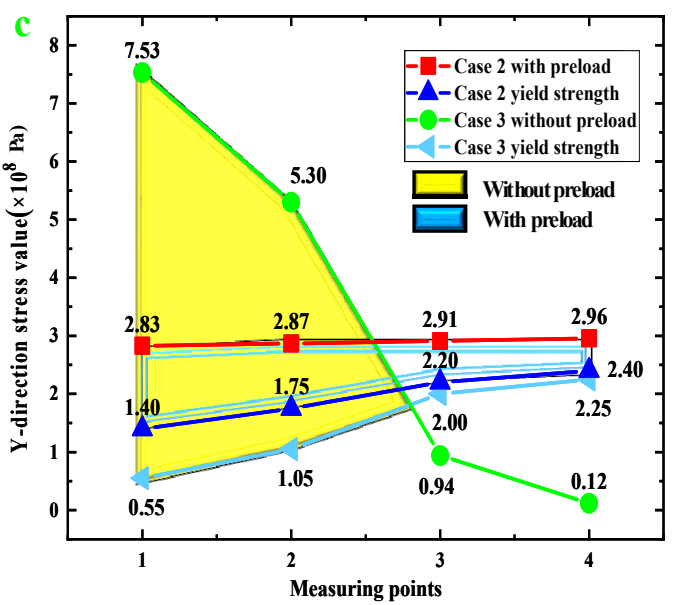

Fig. 4. Stress value comparison of preload and without preload a case 1 with preload and without preload, b case 2 with preload and without preload, and c case 2 and case 3

Fig. 4a shows a comparison of the stress values of negative preload and without preload in case 1 . Fig. $4 \mathrm{~b}$ shows a comparison of the stress values of negative preload and without preload in case 2. Compared with the positive application of preload, the negative preload and the thermal tensile pressure are superimposed in the lower part of the heating zone. This condition results in plastic deformation on the back of the plate. Therefore, measuring points $1,2,3$, and 4 are taken on the back of the plate. By comparing the stress values (Fig. 4b), the stress values with negative preload (2.83 and $2.87 \mathrm{MPa})$ are less than those without preload (7.53 and 5.30 MPa) at points 1 and 2 . The coupled stress values with negative preload (2.91 and $2.96 \mathrm{MPa}$ ) are larger than those without preload $(0.94$ and $0.12 \mathrm{MPa})$ at points 3 and 4 . Therefore, as same as positive preload, the addition of negative preload can also increase the value of the coupling stress at each location and extend the length of plastic deformation zone.

Figure. 4c shows the comparison between negative low-temperature preload (case 2) and without high-temperature preload (case 3). As shown in the figure, the area enclosed by low-temperature negative preload and yield strength is smaller than that enclosed by high-temperature without preload and yield strength. However, with the increase in measuring points, the area gap between low-temperature negative preload and high-temperature without preload gradually narrows.

\section{Conclusions}

The application of preload at low-temperature can increase the bending angle by up to 39 times (positive preload) and 31 times (negative preload) compared with without load. Low-temperature preload can obtain larger bending angle. The addition of preload at low-temperature not only increases the stress value at each plastic deformation point but also extends the length of the deformation area. 


\section{References}

1. J. Li, Z. Su, F. Yao. Hot. Work. Technol. 46 (2017).

2. S. Fu, L. Yang, H. Zhang. Int. J. Precis. Eng Man. 19 (2018).

3. D. P, K. Karuna, D. S. Laser. Man. Mater. Process. (2018).

4. K. Chan, J. Liang. Meter. Let. 49(2001).

5. M. Merklein, T. Hennige, M. Geiger. Mater. Process. Tech. 115 (2001).

6. J. Cheng, J. Zhang, C. Chu, J. Zhe. Int. J. Adv. Manuf. Tech. 26 (2005).

7. J. Cheng, Y. Yao. Manuf. Process. 3 ( 2001).

8. B. Yilbas, A. Arif, B. Abdul. Opt. Laser. Technol. 44 (2012).

9. G. Chen, X. Xu. J. Manuf. Sci. E-T. Asme. 123 (2001).

10. L. Xu, W.D. Li, X.F. Wang. U. Aeronaut. Astronaut. 43 (2017).

11. Y.J. Shi, J. Hu, C. Dong. P. I. Mech. Eng. B-J. Eng. 225 (2011). 